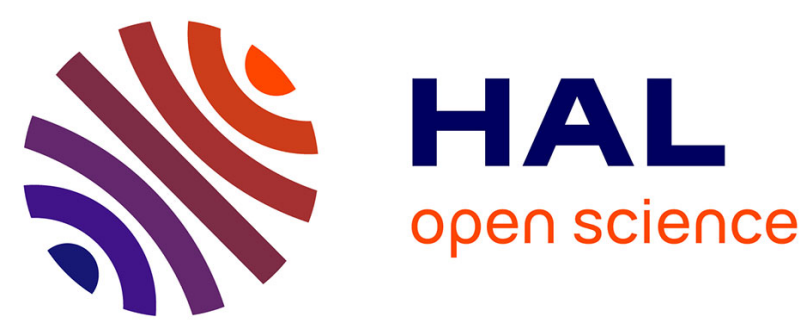

\title{
Urban runoff impacts on particulate metal and hydrocarbon concentrations in river Seine: suspended solid and sediment transport
}

Alexandrine Estèbe, Hacène Boudries, Jean-Marie Mouchel, Daniel R. Thévenot

\section{To cite this version:}

Alexandrine Estèbe, Hacène Boudries, Jean-Marie Mouchel, Daniel R. Thévenot. Urban runoff impacts on particulate metal and hydrocarbon concentrations in river Seine: suspended solid and sediment transport. Water Science and Technology, 1997, 36 (8), pp.185-193. hal-01179957

\section{HAL Id: hal-01179957 \\ https://hal.science/hal-01179957}

Submitted on 23 Jul 2015

HAL is a multi-disciplinary open access archive for the deposit and dissemination of scientific research documents, whether they are published or not. The documents may come from teaching and research institutions in France or abroad, or from public or private research centers.
L'archive ouverte pluridisciplinaire HAL, est destinée au dépôt et à la diffusion de documents scientifiques de niveau recherche, publiés ou non, émanant des établissements d'enseignement et de recherche français ou étrangers, des laboratoires publics ou privés. 


\title{
URBAN RUNOFF IMPACTS ON PARTICULATE METAL AND HYDROCARBON CONCENTRATIONS IN RIVER SEINE: SUSPENDED SOLID AND SEDIMENT TRANSPORT
}

\author{
Alexandrine Estèbe, ${ }^{*}$ Hacène Boudries, ${ }^{*}$ \\ Jean-Marie Mouchel** and Daniel R. Thévenot* \\ *LABAM, Faculté des Sciences et Technologie, Université Paris XII - Val de Marne, \\ 61 Avenue du Général de Gaulle, 94010 Créteil Cedex, France. \\ ** CERGRENE, ENPC-ENGREF, Champs sur Mame, 6-8 Avenue Blaise Pascal, \\ 77455 Marne la Vallée Cedex 2, France
}

\begin{abstract}
Particulate heavy metals and hydrocarbons have been measured in Paris urban area during dry and wet weather periods. A 18 months campaign realised upstream Paris, in the river Seine, has evidenced higher heavy metals concentrations during summer than winter. Summer campaigns demonstrate a strong impact of Paris urban area and its discharges. The direct impact of highly polluted urban overflows into River Seine has been evidenced as a weak immediate but significant retarded discharge of particulate toxic metals. Ratios of significant PAH's allows a better understanding of sources and transport of hydrocarbon in urban areas. Furthermore, relation of these impacts to those observed for heavy metals brings useful information on effects of urban storm drainage. (1997 IAWQ. Published by Elsevier Science Lid
\end{abstract}

\section{KEYWORDS}

Carbon preference index; heavy metals; hydrocarbons; urban runoff; suspended solids.

\section{INTRODUCTION}

Metal pollutants and hydrocarbons, recognised as hazardous compounds, especially polynuclear aromatic hydrocarbon (PAH) (Bomboi and Hernandez, 1991; Hermann, 1981) are heavily present in urban areas. Whatever their origin, they are transported by urban runoff, first to the sewer system, then to the river. Mostly in a particulate form, i.e. fixed to solids, those pollutants are found in the river among suspended solids (SS) and sediments (Hart, 1982; Valiron and Tabuchi, 1992).

Since the levels of SS in a river greatly depend on its hydraulics, pollutants concentrations in particulates have to be monitored during all flow conditions. During summer periods, while the flow rate is low, the impact of a city can be visualised by upstream/downstream comparisons. During high flow periods, the impact of the city or its waste water is less important but floods may resuspend sediments and further transport them downstream. 


\section{METHODS}

\section{Selection of the SS sampling sites}

Four sites were selected in the Paris district to assess urban runoff impact on metal concentrations in the river Seine (Fig. 1):

Vitry, on the river Seine (Port a l'Anglais lock) and Alfortville, on the river Marne (Saint Maurice lock), both sites upstream from Paris, were selected to identify the respective contributions of the river Seine and the river;

Suresnes, downstream from Paris, was selected in order to evaluate the impact of Paris runoff;

Chatou, downstream from Paris and downstream the two largest combined sewer overflows (CSOs) sites known in the Paris area, i.e. Clichy and La Briche, was selected for the annual monitoring of the SS metal concentrations: by comparison with Suresnes data, CSOs impacts were identified.

SS sampling in the river Seine was conducted over periods ranging from several days up to 18 months.

To assess urban runoff impact on composition and concentration of hydrocarbons in the Seine river SS, samples were collected at Chatou, just before and after a CSO event on September 7, 1995. Samples were collected daily between September 7 to September 12, 1995.

\section{Sampling techniques}

Devices used for sampling in lakes and seas (Blomqvist and Hakanson, 1981; Gardner, 1980a, b) were adapted to design new SS settling traps (Estèbe et al., 1997). Our trap $(50 \mathrm{~cm}$ depth, and $30 \mathrm{~cm}$ internal diameter), equipped with a honeycomb filling, was placed $40 \mathrm{~cm}$ below the water surface and $1.5 \mathrm{~m}$ from the bank of the river Seine.

Two types of sediment sampling devices were used: 1) a core sampler and 2) a device derived from the Hansel bottle. The latter includes a large and heavy base to ensure the stability of the system while resting at the bottom. The 1-2 I sampling bottle, set upside down, ends with a funnel in contact with the sediment surface. Hydrostatic pressure $(5-8 \mathrm{~m})$ allows surface sediment to enter rapidly into the sampling bottle.

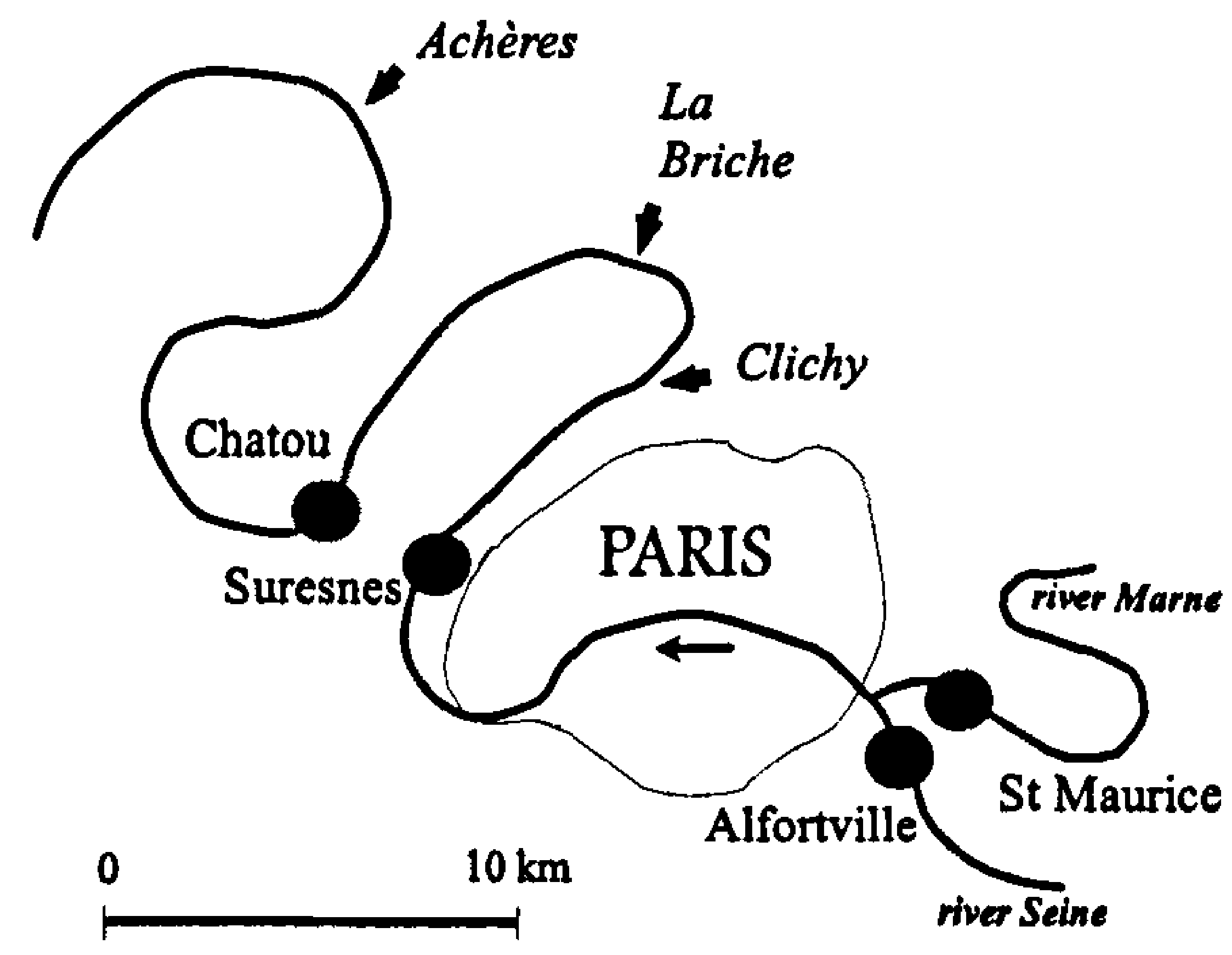

Figure 1. River SS and sediment sampling sites. 


\section{Heavy metals extraction and analysis}

SS samples, collected daily or weekly with traps, were quickly transported to the laboratory, centrifuged and dried. Metal extraction was conducted with heated concentrated acids $\left(18: 2\right.$ vol./vol. $\left.\mathrm{HNO}_{3} / \mathrm{HClO}_{4}\right)$ (Marchandise et al., 1982; Flores-Rodriguez, 1992). Heavy metals ( $\mathrm{Fe}, \mathrm{Cd}, \mathrm{Cu}, \mathrm{Pb}$, and $\mathrm{Zn}$ ) were then analysed by flame atomic absorption spectrophotometry (AAS). The same procedure was applied for sediments.

\section{Hydrocarbons extraction and analysis}

The samples were collected from the bottom of traps into 2.51 glass bottles and transported rapidly ( $2-3 \mathrm{~h}$ ) to the laboratory for centrifugation $\left(3700 \mathrm{rpm}, 20 \mathrm{~min}\right.$ ) and drying at $60^{\circ} \mathrm{C}$. This treatment stabilises the composition of hydrocarbons in the sample before analysis and was shown to be as efficient as lyophilisation for solvent extraction. No significant losses of the lower hydrocarbons have been observed.

About $4 \mathrm{~g}$ of dry SS were extracted for $24 \mathrm{~h}$ under subdued light with a mixture of $\mathrm{CH}_{2} \mathrm{Cl}_{2}$ and $\mathrm{CH}_{3} \mathrm{OH}(5: 1$, $\mathrm{v} / \mathrm{v}$ ) in a Soxhlet apparatus with internal standard hydrocarbons added (Phenanthrene- $\mathrm{D}_{10}$ and Pyrene- $\mathrm{D}_{10}$ as aromatic standards and Tetracosane- $\mathrm{D}_{50}$ as the aliphatic hydrocarbon standard). The extract was dried by $\mathrm{Na}_{2} \mathrm{SO}_{4}$ and concentrated down to $5 \mathrm{ml}$, using rotary evaporation. All solvents or chemical product used were distilled or extracted in a Soxhlet apparatus.

The extracts were evaporated under a flux of pure nitrogen down to $1 \mathrm{ml}$ and separated by adsorption chromatography using a glass micro-column filled with $2 \mathrm{~g}$ of deactivated Silica gel and elution with a series of solvents of increasing polarity. Two fractions were obtained by elution with n-hexane $(5 \mathrm{ml})$ and $20 \%$ of dichloromethane in $\mathrm{n}$-hexane $(3 \mathrm{ml})$, corresponding, respectively to the aliphatic and poly-aromatic hydrocarbons. Both fractions were then further evaporated to $0.25 \mathrm{ml}$ under a flow of pure nitrogen.

The analysis of each column eluting fraction was carried out with a Hewlett-Packard GCD, gas chromatography-mass spectrometer (GC/MS) system equipped with PONA capillary column (Hewlett Packard, 95\% methyl silicone, $50 \mathrm{~m}$ length, $0.20 \mathrm{~mm}$ i.d., $0.45 \mathrm{~m}$ film thickness) coupled directly to the mass spectrometer. The oven temperature was programmed from 70 to $300^{\circ} \mathrm{C}$ at $2^{\circ} \mathrm{C} \cdot \mathrm{min}^{-1}$. Hydrogen was used as a carrier gas at constant flow $\left(1 \mathrm{ml} \cdot \mathrm{min}^{-1}\right)$. The mass spectrometer scanned repeatedly from 10 to $450 \mathrm{Da}$ at one scan per second and the ionisation electron energy was $70 \mathrm{eV}$.

\section{RESULTS AND DISCUSSION}

\section{Annual variations of metal concentrations in river Seine SS downstream from Paris}

River Seine SS was sampled at Chatou between June 1992 and September 1993. Whereas SS levels in river Seine increase significantly with flow rate, their volatile content (VSS) is more stable and decreases during highest flow periods. Fluctuations of the iron concentration, around the average value of $25 \mathrm{~g} / \mathrm{kg} \mathrm{d}$.w., appear to be independent of the river flow. For a trace element such as cadmium (Fig. 2), variations are much more important than for iron. Over this 18-month study, high concentrations were observed during low flow periods and low concentrations during high flow periods. During summer, concentration peaks can be clearly identified. Other trace elements show similar results. 


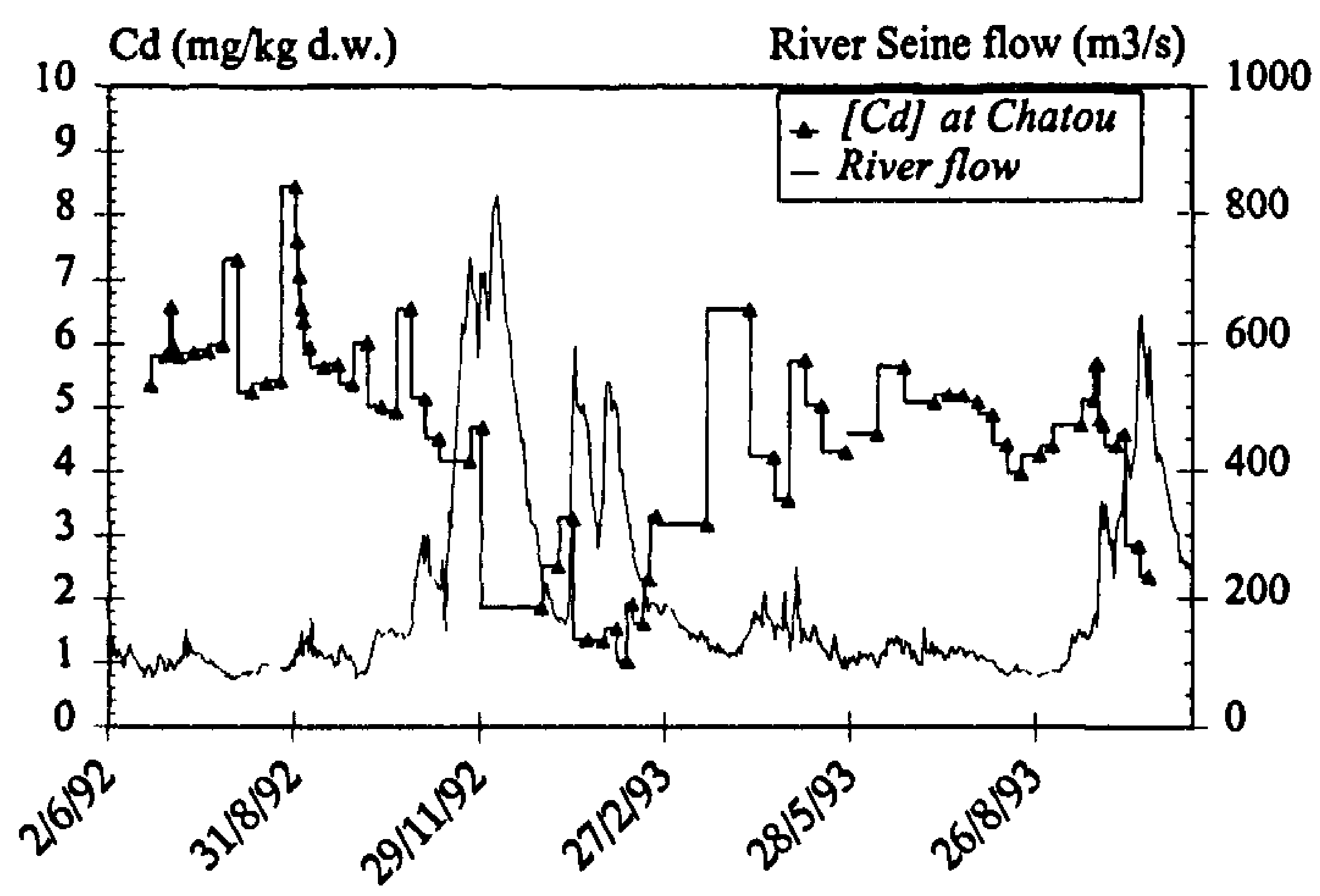

Figure 2. Cadmium concentration variation in river Seine SS at Chatou between June 1992 and September 1993, and average daily flows of the river at Paris.

\section{Metal and hydrocarbon concentration variations in river Seine downstream from Paris during the summer}

Heavy metals. Cadmium concentrations (Fig. 3) in SS are significantly higher downstream from Paris. This is clearly observed when comparing data collected at Vitry (Port a l'Anglais lock) and Alfortville (Saint Maurice lock) to those at Suresnes, but also when comparing Suresnes data to Chatou data. Such concentration increases clearly indicate the chronic impact of greater Paris on the river Seine. Moreover, particulate cadmium concentrations present peaks at Chatou after large CSO events, identifying the impact of these urban runoffs. Similar results were found for the other trace metals. Another peak in the particulate cadmium concentration was also observed during dry weather periods: it is probably related to an accidental industrial nunoff.

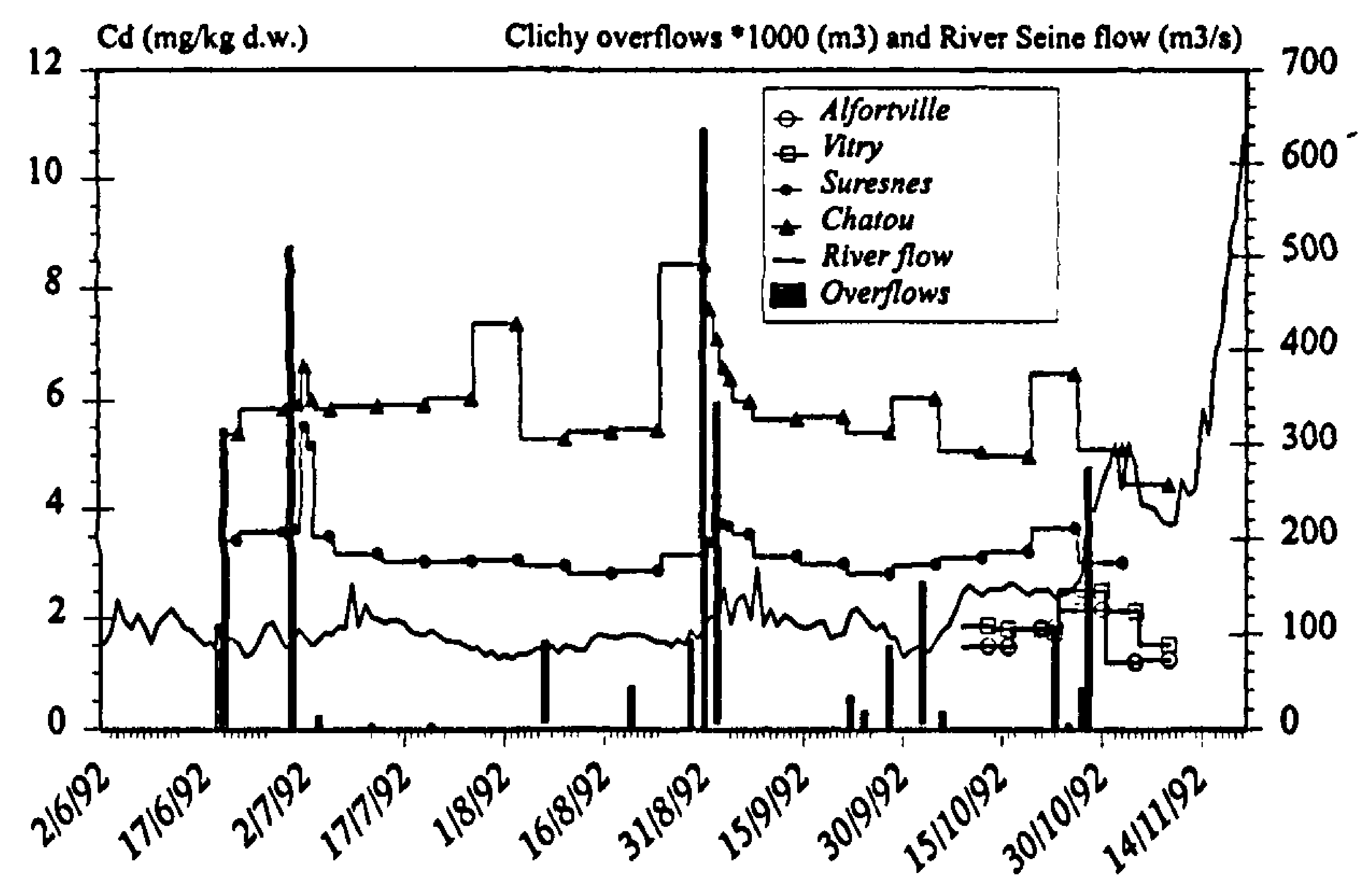

Figure 3. Cadmium concentration variations in river Seine SS from up- to downstream from Paris during summer 1992 (see Fig. 1 for site location). 
A survey of river Seine surface sediment and its trace metal level during summer 1994, shows larger spatial variations in the right side of the river Seine rather than in the left one (Fig. 4). It should be noted that sediments could not be collected everywhere because the bottom is made of rocks in some areas of the river. In particular, near the right bank of the right side, two concentration increases were observed:

a limited one, starting between kilometric points 23 and 24, and extending on the right bank until kilometric point 29.5 and on the left bank, until 33;

a broader one from kilometric point 29.5 to 38.

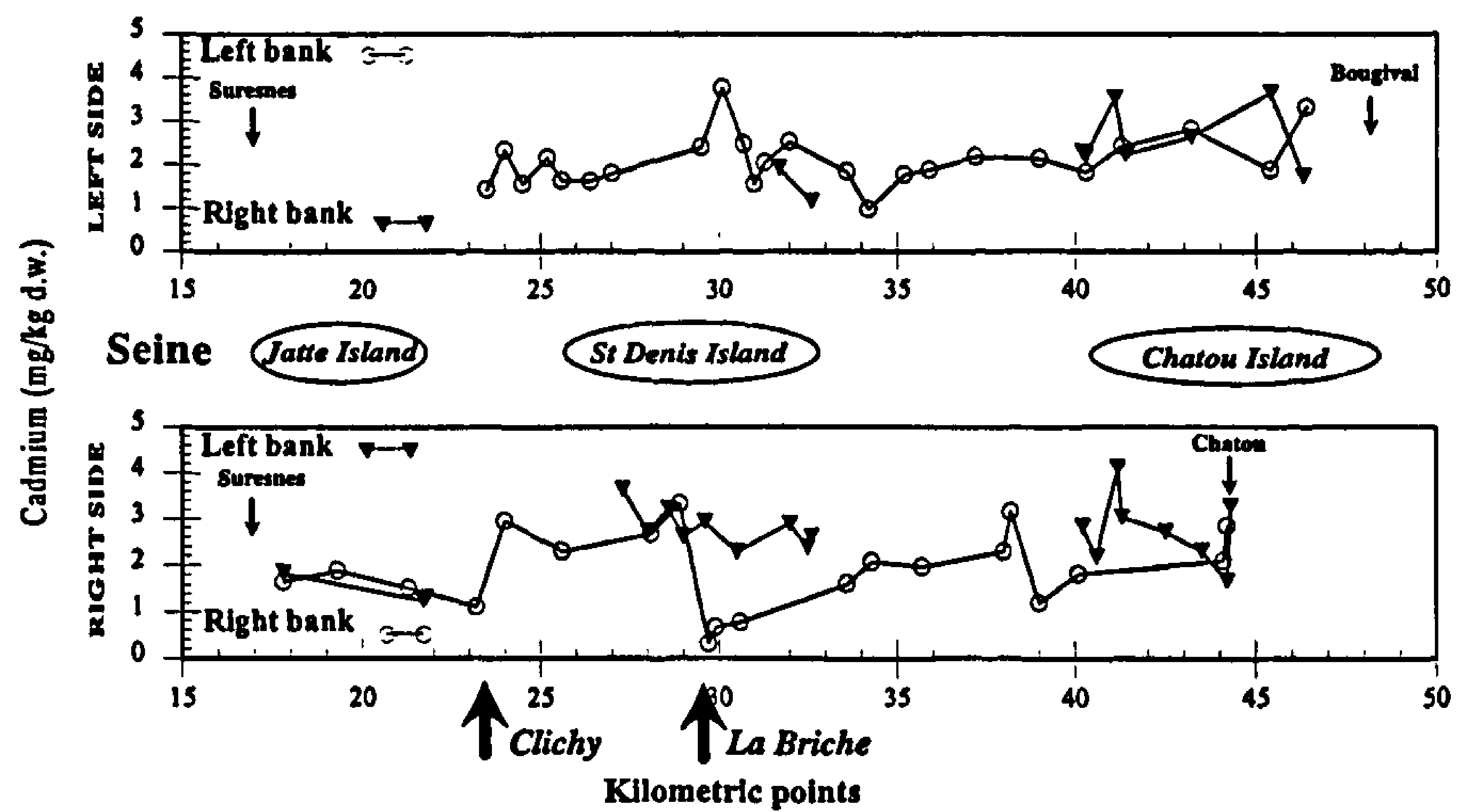

Figure 4. Cadmium concentration in river Seine sediment downstream from Paris, during summer 1994.

The first increase in concentration may be related to the Clichy urban runoff: CSO's impact is observed on the right bank where overflows occur. Cadmium levels on the opposite bank are similar, suggesting a dispersion of particles over the whole river width. The second increase could be attributed to La Briche overflows: their impact is more progressive but sediment concentrations are similarly high, $5 \mathrm{~km}$ downstream from the site. The sharp decrease of trace metal concentration, just at La Briche outlet, is likely to be related to an intense navigation activity, which mobilises the finer fraction of sediments close to Saint Denis canal lock (on kilometric point 29.5).

Hydrocarbons. The impact of the September 7, 1995 CSO event appears clearly on variation of SS concentrations which increase from 16 to $31 \mathrm{mg} .1^{-1}$ before returning, within $24 \mathrm{~h}$, to $11-12 \mathrm{mg} .1^{-1}$ (Table 1). During that wet period, river Seine flow, at Austerlitz bridge in Paris, increases gradually from 150 to $200 \mathrm{~m}^{3} \cdot \mathrm{s}^{-1}$ with a small peak at $190 \mathrm{~m}^{3} \cdot \mathrm{s}^{-1} 2$ days after the CSO event, i.e. when the Clichy and La Briche CSOs reach Chatou.

We observe on chromatograms of SS extracts more than 20 aliphatic $\left(C_{11}-C_{36}\right)$ and 15 polycyclic aromatic well identified and quantified hydrocarbons but also an unresolved complex mixture (UCM). Table 1 shows that, during this one week sampling period including a CSO impact, concentrations of resolved aliphatic hydrocarbons increased from 75 to $162 \mu \mathrm{g} \mathrm{g}^{-1}$ dry SS whereas PAHs concentrations increased from 7 to 14 $\mu \mathrm{g} \mathrm{g}^{-1}$ dry SS. This factor 2 increase of concentrations of both types of hydrocarbons is similar, in amplitude, to the heavy metal concentration increase in SS after a CSO event. However, the fate of hydrocarbons seems significantly different from that of metals. The increase of hydrocarbon concentrations lasts several days after the overflow event although the water transfer time between Clichy urban nunoff site and Chatou is limited to 2 days. This different behaviour may indicate a difference of mechanism of pollution transport by CSO SS which have been shown to rapidly settle and then slowly migrate on the bottom of river Seine. 
Table 1. Concentration and hydrocarbon composition of Seine river SS at Chatou (5-12 September 1995)

\begin{tabular}{|c|c|c|c|c|c|c|c|}
\hline Sampling date & $\begin{array}{l}\text { Sept. 5-6 } \\
1995\end{array}$ & $\begin{array}{l}\text { Sept. } 7 \\
1995\end{array}$ & $\begin{array}{l}\text { Sept. } 8 \\
1995\end{array}$ & $\begin{array}{l}\text { Sept. } 9 \\
1995\end{array}$ & $\begin{array}{l}\text { Sept. } 10 \\
1995\end{array}$ & $\begin{array}{l}\text { Sept. } 11 \\
1995\end{array}$ & $\begin{array}{l}\text { Sept. } 12 \\
1995\end{array}$ \\
\hline $\begin{array}{c}\text { Instantaneous SS concentration } \\
\left(\mathrm{mg} \mathrm{l}^{l^{-1}}\right)\end{array}$ & 16.1 & 31.1 & 18.1 & 12.5 & 10.7 & 11.8 & 11.3 \\
\hline SS weight in settling trap $(\mathrm{g})$ & 68.5 & 37.6 & 15.2 & 15.9 & 16.3 & 18.7 & 17.1 \\
\hline Seine river flow $\left(\mathrm{m}^{3} \mathrm{~s}^{-1}\right)$ & 149 & 180 & 188 & 174 & 165 & 174 & 201 \\
\hline$\Sigma$ n-alcanes $\mathrm{HC}\left(\mu \mathrm{g} \mathrm{g}^{-1}\right)$ & 75.7 & 131.9 & 162.3 & 149.0 & 123.4 & 144.2 & 148.0 \\
\hline$\Sigma$ aromatic $H C\left(\mu g g^{-1}\right)$ & 7.56 & 10.3 & 9.6 & 11.6 & 14.3 & 12.0 & 11.2 \\
\hline $\operatorname{UCM}\left(\mu g g^{-1}\right)$ & 1741 & 3003 & 2133 & 3854 & 2139 & 4172 & 2946 \\
\hline Global CPI & 1.96 & 1.59 & 1.44 & 1.55 & 1.88 & 1.71 & 1.17 \\
\hline $\mathrm{CPI}\left(<\mathrm{C}_{20}\right)$ & 2.13 & 1.18 & 0.98 & 0.96 & 1.07 & 0.97 & 0.78 \\
\hline CPI $\left(>C_{20}\right)$ & 1.87 & 2.65 & 2.76 & 2.29 & 3.95 & 4.96 & 3.01 \\
\hline
\end{tabular}

\section{Distribution of n-alkanes}

Figure 5 shows the distribution of particulate $C_{11}-C_{36}$ n-alkanes from September 5 to 12, 1995. We can observe two maximum concentrations, respectively for $\mathrm{C}_{17}$ and $\mathrm{C}_{29}$, and a minimum concentration corresponding to $\mathrm{C}_{20}-\mathrm{C}_{21}$ together with, in general, an odd carbon-numbered predominance. If we consider now two classes of aliphatic hydrocarbons, the first one corresponding to lighter $n$-alkanes $C_{11}-C_{20}$ and the second class to heavier ones, i.e. $\mathrm{C}_{21}-\mathrm{C}_{36}$, we can observe a difference in the distribution of aliphatic hydrocarbons from one day to another. Before the CSO event of September 7, the sample taken on September 5, shows high concentrations of heavier hydrocarbons $\left(C_{21}-C_{36}\right)$ and very low level concentrations for lighter hydrocarbons, except $C_{17}$. An opposite distribution is observed for the September 7 and 8 samples, which correspond to the period of the CSO event: we observe higher level of concentration for the $C_{11}-C_{20}$ n-alkanes.

\section{Carbon preference index (CPI)}

The CPI represents the ratio between the odd and even-carbon aliphatic hydrocarbons. We have calculated 3 different CPIs (Table 1): the first one, corresponds to all hydrocarbons measured $\left(C_{11}-C_{36}\right)$, the second and the third one correspond, respectively, to the lighter hydrocarbons, i.e. $C_{11}-C_{20}$, and to the heavier ones, i.e. $\mathrm{C}_{21}-\mathrm{C}_{36}$. We observe that for the first group, i.e. $\mathrm{C}_{11}-\mathrm{C}_{20}$, the CPI decreases from 2.13 to below 1 after the CSO impact. This suggests a significant predominance of even-carbon numbered aliphatic hydrocarbons and might indicate a recent petrogenic contamination (Readman et al., 1986). Several studies (Broman et al., 1987) have already shown that fuel oil products exhibit similar low range n-alkanes distribution. In the higher carbon-number range, i.e. $\mathrm{C}_{21}-\mathrm{C}_{36}$, we observe an increase of the concentration level with always odd-carbon numbered predominance after the overflow (September 8): it is very difficult to distinguish between the natural and anthropogenic sources, due to the value of CPI between 2-5, in spite of dominant $n$ $C_{27}, n-C_{29}$ and $n-C_{31}$, which are indicative of a natural higher plant input (Readman et al., 1986). 

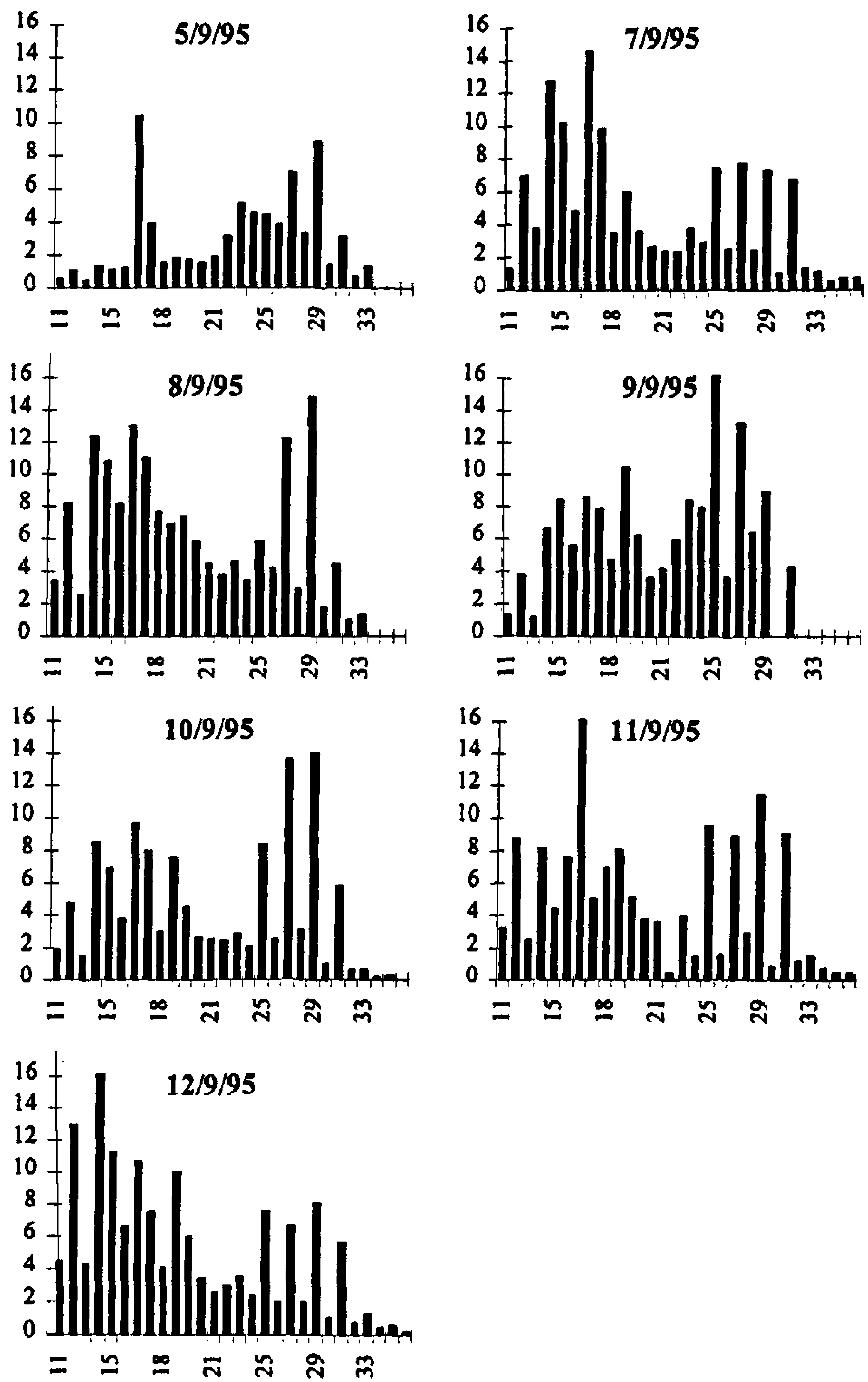

Figure 5. Distribution of $n$-alkanes, in $\mu \mathrm{g} \mathrm{g}^{-1}$ dry SS, according to their number of $\mathrm{C}$ atoms, between September 5 and 12, 1995 in Seine River, at Chatou.

\section{Metal concentration variations in river Seine SS downstream from Paris during winter}

A plot of trace metal concentrations versus river Seine flow rate, during the January-February 1993 flood period (Fig. 6), shows an hysteresis curve. At the beginning of the flood period, cadmium concentrations increase significantly. Such variation indeed corresponds to the ending of the preceding floods and the establishment of a lower flow regime. The decrease of river flow rate yields, with some delay, a decrease of SS cadmium levels. It is due to the arrival, at Chatou, of less polluted SS probably originating from less urbanised and industrialised upstream areas. Similar behaviour has been observed for lead, zinc and copper. 


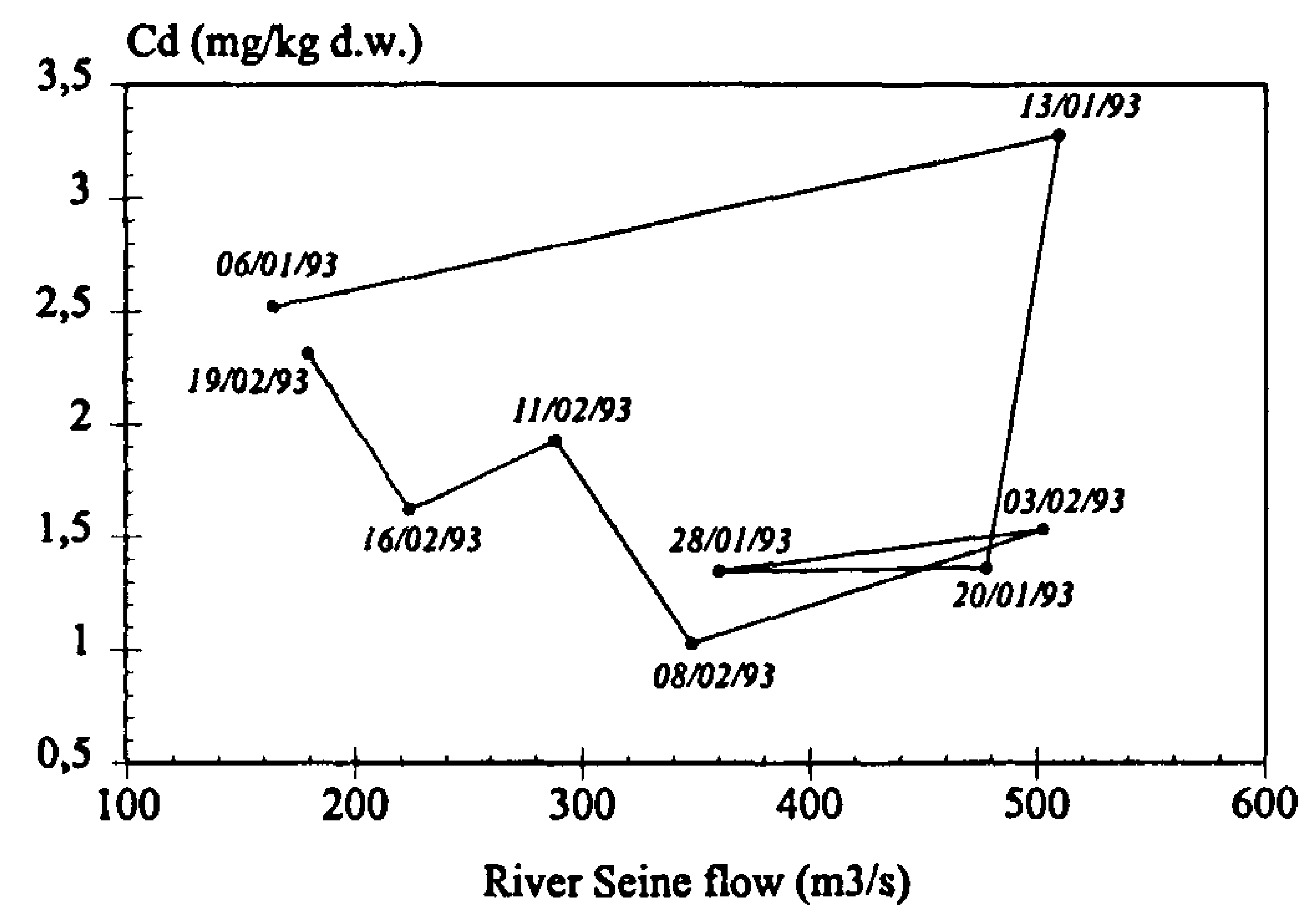

Figure 6. Cadmium concentrations in river Seine SS, at Chatou, as a function of the flow rate during winter 1993.

This hypothesis is confirmed by the severe difference in cadmium concentration in two sediment cores sampled at Chatou just before and after the October 1993 flood (Fig. 7). The cadmium disappearance in the first $20 \mathrm{~cm}$ of sediment layer can be attributed to the erosion of the surface sediments by the increase of flow rate and to settling of SS originating from less polluted upstream areas.

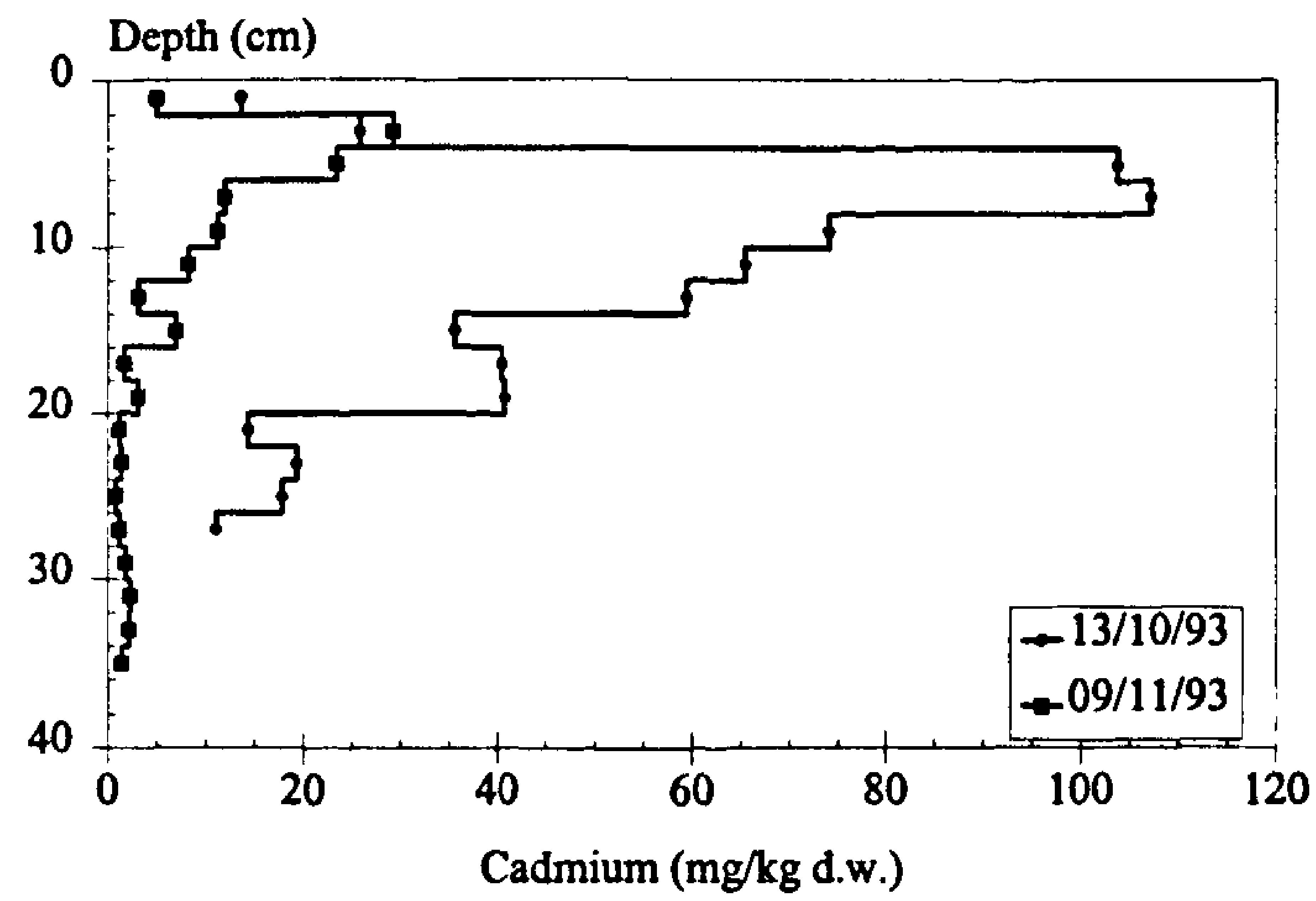

Figure 7. Cadmium concentration in the river Seine sediment at Chatou, just before and after the October 1993 flood period $\left(650 \mathrm{~m}^{3} / \mathrm{s}\right)$

\section{CONCLUSION}

This study has evidenced the presence of heavy metals fixed on SS found in the river Seine at higher concentrations during summer than winter. Such difference can be attributed to both the discharge of the CSOs into river Seine and to the urban versus rural origin of the SS.

During summer, metal concentrations increase as the sampling point is located further downstream from Paris. Such a difference indicates a chronic impact of Paris and its district on the quality of the river Seine. Peak concentrations of trace metals fixed on SS were observed downstream Paris during major CSO events, thus demonstrating the impact of these discharges. However, the mass balance comparison of the trace 
metals issued from CSOs to those actually measured in the river Seine indicate that most of the SS originating from these discharges settle within a few days. A significant impact of Paris CSO has been also demonstrated on the basis of total aliphatic and aromatic hydrocarbons linked to SS present in the river Seine. During this CSO event contribution of hydrocarbons is observed with a significant concentration of lighter $n$-alkanes, i.e. $C_{11}-C_{21}$, with even-numbered carbon predominance: these hydrocarbons are typically anthropic (CPI <1).

During winter periods, strongly polluted urban SS are resuspended and transported downstream while being replaced by less polluted SS originating from rural districts. If the local impact of the toxic metal discharges from the urban areas is somewhat limited, the winter flood periods of the river Seine tend to move the impact zones of these discharges further downstream towards the estuary.

Therefore, several time scales can be identified for the cycle of metal pollutants in urban runoff. From an hourly time scale, in the description of CSOs and SS settling, one has to consider a weekly, monthly or even yearly scale for describing SS transport through sediment erosion and settling.

\section{ACKNOWLEDGEMENTS}

Authors acknowledge the support of PIREN-Seine programme (CNRS GDR 1067).

\section{REFERENCES}

Blomqvist, S., Hakanson, L. (1981). A review of sediment traps in aquatic environment. Archiv für Hydrobiol., 91, $101-132$.

Bomboi and Hernandez, A. (1991). Hydrocarbons in urban runoff: their contribution to the wastewaters. Atmos. Environ, 25, 557565.

Broman, D., Colmsjo, A., Ganning, B., Naf, C., Zebuhr, Y. and Ostman, C. (1987) Fingerprinting petroleum hydrocarbons in bottom sediment, plankton, and sediment trap collected Seston. Mar. Pollut. Bull., 18, 380-388.

Estèbe, A., Mouchel, J. M. and Thévenot, D. R. (1997). Urban runoff impacts on particulate metal concentrations in River Seine., Wat. Air Soil Pollut.,(in press).

Flores-Rodriguez, J. (1992). Les métaux toxiques dans les eaux pluviales en milieu urbain : caractéristiques physico-chimiques. Ph. D thesis, University Paris XII-Val de Marne, 229 pp.

Gardner, W. B. (1980a). Sediment trap dynamics and calibration: a laboratory evaluation. J. Mar. Res., 38, 17-39.

Gardner, W. B. (1980b). Field assessment of sediment traps: a laboratory evaluation. J. Mar. Res., 38, 41-52.

Hart, B. T. (1982). Uptake of trace metals sediments and suspended particulates: a review. Hydrobiologia, 91, $299-313$.

Hermann, R. (1981) Transport of polycyclic aromatic hydrocarbons through a partly urbanised river basin. Wat. Air Soil Pollut., 16, 445-467.

Marchandise, P., Olié, J. L., Robbe, D. and Legret, M. (1982). Diverse methods of mineralization trace metals determination in river sediment and sewage sludges? Inter-laboratory comparison of extraction techniques. Environ. Tech. Lett., 3, 157166.

Readman, J. W., Preston, M. R. and Mantoura, R. F. C. (1986). An integrated technique to quantify sewage, oil and PAH pollution in estuarine and coastal environments. Mar. Pollut. Bull., 17(7), 298-308.

Valiron, F. and Tabuchi, J.-P. (1992). Maîtrise de la pollution urbaine par temps de pluie, état de l'art. Lavoisier Tec \& Doc, Paris, 564 pp. 